\title{
Comparative Study on the Effect of Nitriding and Microwave Coating on Microstructure, Hardness and Wear of AISI H13 Tool Steel
}

\author{
Mohammad Iqbal Yunus ${ }^{{ }^{*}}$, Kanwarjeet Singh ${ }^{\dagger}$, Gaurav Arora ${ }^{\dagger}$ and Ranganath M Singari ${ }^{\dagger}$ \\ †Department of Tool Engineering, Delhi Institute of Tool Engineering, Okhla, New Delhi, India \\ tDepartment of Mechanical Engineering, Delhi Technological University, Shahbad Daulatpur, Delhi, India
}

Received 25 May 2018, Accepted 28 July 2018, Available online 30 July 2018, Vol.8, No.4 (July/Aug 2018)

\begin{abstract}
Heat treatment and surface processing are critical aspects of design and manufacture of components in a wide range of industrial sectors. Engineering materials, such as steel, are heat treated under controlled heating and cooling to alter their chemical, physical and mechanical properties to meet desired engineering applications. Gears engaged rotating at several thousand RPM. Inner Barrels of Injection Moulding machines, which is subjected to wear when thermoplastics, glass fibres are chosen to be injection moulded, Guide pillar Guide bush which slide over each other needs to be hardened from outside to improve hardness and wear resistance, but ductile from inside to bear fluctuating load, for this types of operation Case Hardening is required, to give desired property. In this detailed and systematic investigation, we have selected AISI H13 tool steel as for our research work specimen and we have made an effort to find out the mechanical properties (EDX, Hardness HV, Pin on Disc wear test) and micro structural properties (SEM, XRD) by comparing the two process one is traditional Case hardening heat treatment process i.e. Gas Nitriding and a new process i.e. Coating of Ni-based alloy powder on H13 Tool steel by Microwave Hybrid Heating (MHH) method in household microwave oven at $900 \mathrm{~W}$ and $2.45 \mathrm{GHz}$ and further find the best process. Investigation shows that coated Sample has good Wear resistance as compared to unmodified H13 Tool Steel sample and nitrided sample, Vicker's micro-hardness of nitride sample is found to be $829.5 \mathrm{HV}$, and for coated sample is $788 \mathrm{HV}$, Coated sample has good Microstructure as compared to nitrided sample and is free from porous cracks.
\end{abstract}

Keywords: 113 Tool Steel, Microwave Hybrid Heating, Case-Hardening, Gas Nitriding, Ni-based Alloy, Microwave Coating, EDX, XRD, SEM, Pin on Disc Wear Test

\section{Introduction}

In the fast-growing economy, the need of people is growing day by day, that's is why growth of plastics and hybrid materials have improved, which has a good impact in the growth of tooling, extrusion and injection moulding industry. A large amount of time is being wasted in maintenance, care and sustenance, of tooling and injection moulding equipment.

Heat treatment is one of the major time consuming and tedious job to do in the industry for getting desirable property, case hardening further become more important to get desirable property Because hardened metal is normally more brittle than softer metal, through is not always a suitable choice for uses where the metal part is subject to sliding contact with hard or abrasive materials case-hardening provides a part that will not fracture (because of the soft core that can absorb stresses without cracking and hard outside which can bear sliding wear) but also satisfactorily resist wearing on the surface.

*Corresponding author's ORCID ID: 0000-0002-1184-8133 DOI: https://doi.org/10.14741/ijcet/v.8.4.21
Further again if we talk about different case hardening techniques used nowadays require at least minimum of 5 hours for case hardening, further every process is not capable of performing for every metals or alloys.

Also, application of Physical vapour deposition to develop hard coatings to the substrate materials, cannot assure the optimal tribological performance without pre-treatment of the substrate materials due to plastic deformation of the substrate which results in eventual coating failure. The surface treatment provides a hardening and increases load support on substrate [Zeghni et al, 2005].

Many methods aim to enhance the load bearing capacity of the coated surfaces and improve the adhesion of the coatings such as deposition of an interlayer material or compound prior to the coating or the treatment of the surface by nitriding or carburising. In terms of the cost and simplicity, surface treatment such as nitriding and carburising are better processes [Zeghni et al, 2005]. But at the same time the process is very tedious and time consuming. 
The innovative technique should have low cycle time, low power consumption, low cost, and be environmental friendly [Singh et al, 2016].

In $\mathrm{MHH}$, volumetric irradiation takes place inside the material body caused volumetric heating. In volumetric irradiation, the processing time and the energy requirements gets shorten, which leads to uniform change in material properties throughout the material [Srinath et al, 2011]. Different range of material can be quickly and easily heated by EM energy rather than conventional types of heating because the efficiency of conversion from Electro-Magnetic radiation to heat is nearly $100 \%$. In microwave processing, volumetric heating is done by direct transfer of energy to the bulk through interaction of EM waves with atoms and molecules of the bulk [Srinath, et al, 2011]. Here heat is generated internally within the material and is transferred outwards rather than origination from outside as in conventional heating . So the heating profile is inverse i.e. 'inside-out' unlike the 'outside-in' profile in conventional heating [Aravindan et al, 1999].

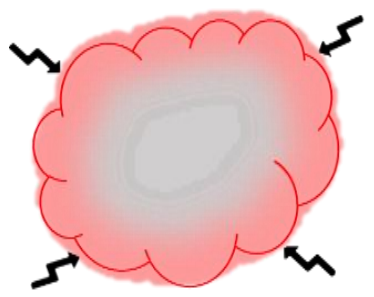

(a)

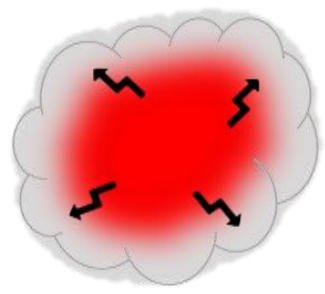

(b)
Fig.1 (a)Conventional heating versus (b)microwave heating [S. Singh et al, 2015]

This investigation, based on the facts stated above, intended to find out the optimum case hardening process by comparing the two processes i.e. through Gas Nitriding process and second is Coating of Ni-based Alloy Powder by Microwave Hybrid heating on substrate i.e. H13 Tool Steel and further characterization of process through Scanning Electron Microscope (SEM) to check Microstructure, X- Ray Diffraction (XRD) to check new phases developed and significance of those phases, Pin on disc wear test to check wear resistance of the specimen and microhardness to check improvement in the hardness properties after the two operation, Further develop and effective process which can be implemented in the industries and help them minimise their maintenances time.

\section{Materials and Methods}

The H13 tool steel substrate of $10 \times 10 \times 5 \mathrm{~mm} 3$ size was prepared by different machining process for the development of Gas Nitrided and Microwave Coated surface. H13 Tool Steel is a Cr-Mo hot work steel that is widely used in hot and cold work applications. Such as hot extrusion dies [Akhtar et al, 2009]. The spectroscopy result of the $\mathrm{H} 13$ tool steel substrate was $0.401 \%$ C, $1.01 \% \mathrm{Si}, 0.439 \% \mathrm{Mn}, 0.004 \% \mathrm{~S},<0.015 \% \mathrm{P}$, $5.11 \% \mathrm{Cr}, 0.066 \% \mathrm{Ni}, 1.31 \% \mathrm{Mo}, 0.89 \% \mathrm{~V}$.

The nominal composition of Ni-based coating powder as per EDX result was $10.65 \% \mathrm{Cr}, 5.66 \% \mathrm{C}$, $3.66 \% \mathrm{Fe}, 2.3 \% \mathrm{Si}, 2.10 \% \mathrm{~V}, 1.98 \% \mathrm{Mn}, 1.60 \% \mathrm{Mo}$, $1.8 \% \mathrm{~B}, 0.02 \% \mathrm{~F}$, and Bal. $\mathrm{Ni}$ (wt.\%), the particle size of Ni-based powder was 50-70 micron. Ni-based coating powders are frequently used to improve the hardness for combating wear-, corrosion-, and heat-resistant properties [Kaushal et al, 2015, Kaushal et al, 2016].

\section{2. a Gas Nitriding}

Gas Nitring samples are fine grounded with 1000 grit Silicon emery paper and further ultrasonically cleaned in acetone $\left(\mathrm{C}_{3} \mathrm{H}_{6} \mathrm{O}\right)$, before nitriding. Samples are then put in closed furnace with maintaining $520 \pm 30^{\circ} \mathrm{C}$ for $72 \mathrm{hrs}$. gas mixture of $\mathrm{NH}_{3}$ and $\mathrm{N}_{2}$ in the ratio of $1: 1$ is flown in the chamber at the rate of $0.6 \mathrm{ml} / \mathrm{min}$ [SH Yeh et al, 2011]. After 72 hrs gas supply is shut-off and continue for another $48 \mathrm{hrs}$ at the same temperature, further samples are allowed to cool in an open air. The sample was heat treated at local heat treatment company i.e. M/s Coatwell India Pvt. Ltd. where proper arrangements for environmental control is accomplished by using vacuum furnace to prevent leakage of gas which causes decarburization.

\section{2. $b$ Microwave Coating}

At room temperature, most of the metals reflect back microwaves and does not allow its penetration through the bulk due to the presence of thick electron blanket Hence, it is difficult to coat metallic materials using microwave irradiation. But heating is due to microwave-material interaction at molecular level, if Microwave of $2.45 \mathrm{GHz}$ freq. is used it means that atoms of that bulk material rubs together 2.45 billion times within a short duration of time, which causes generation of friction within the molecules and thus heating. A number of trials have been made in order to take care of these processing challenges. The following section describes the experimental procedure adopted for generation of bulk metallic clads (Fig- 2) and further different characterisation techniques employed to investigate the clad properties.

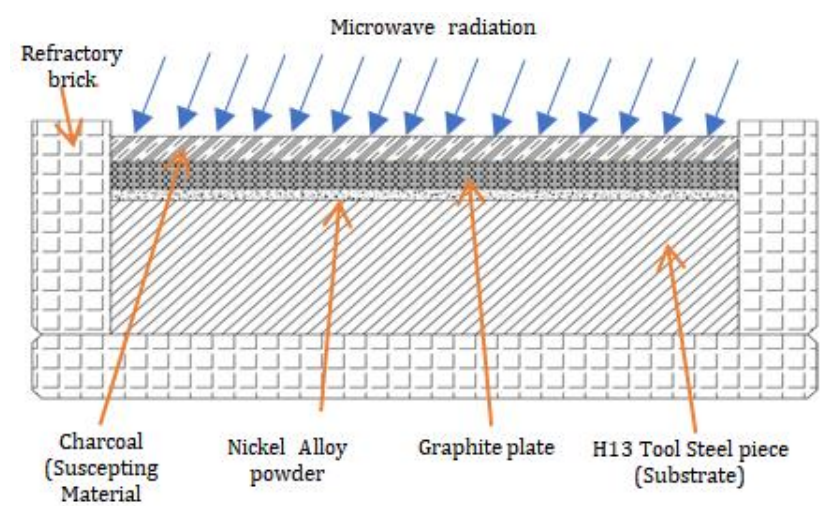

Fig 2 A Section view of the experimental setup for Microwave Cladding 
In the present investigation, unmodified and modified coatings were developed at a constant power of $900 \mathrm{~W}$ while varying the irradiation time interval of $60 \mathrm{~s}$ from 330 to $810 \mathrm{sec}$ for pilot experiments.

In the first step all the specimens are mechanically polished with 1000 size grit emery paper, ultrasonically cleaned in acetone $\left(\mathrm{C}_{3} \mathrm{H}_{6} \mathrm{O}\right)$, Finally dried, before Cladding (coating), Experiments were carried out in $900 \mathrm{~W}, 2.45 \mathrm{Ghz}$ frequency multimode microwave system of ONIDA make (Model -28CJS14). All experiments were carried out in controlled atmospheric condition.

The microwave penetration depth into the bulk material surface is much lesser than the size of bulk metallic pieces $(0.12 \mu \mathrm{m})$ [Gupta et al, 2011]. This leads to throwing back of microwaves from the attacked material. In order to prevent this, use of refractory brick was used as an insulating mask. The bulk pieces were covered and sealed with refractory bricks as shown in the schematic setup in Fig 2, For initial coupling of microwaves with $\mathrm{H} 13$ tool steel pieces at the top of the Clad, a absorber is used which is called susceptor, charcoal powder was used in this case as it has high microwaves absorbing and high heat generating power. Carbon from charcoal does not go inside the bulk steel pieces during microwave heating as a graphite plate (1.5 mm thick) was used to separate the charcoal powder and the sandwich layer powder [Dwivedi, et al, 2014]. Charcoal powder enables the application of principle of microwave hybrid heating (MHH) to Clad Ni- based powder on the surface of H13 metallic pieces. The charcoal powder was placed on the top of the graphite plate. The susceptor material ingests microwave promptly at room temperature until it reaches a higher temperature, which is then transferred to the coating powder (Ni-based powder) via the conduction or radiation heat transfer until it starts absorbing microwave radiation directly at higher temperature normally between $500 \pm 100^{\circ} \mathrm{C}$. As a result, the metallic materials start coupling with microwaves at higher temperature leading to further rise in temperature. The temperature rise is sufficient to cause melting and fusing of the interfaces and gives metallurgical bonding. Fig 3 gives the detailed stepwise description of microwave cladding.

Table 1 Mechanical properties of H13 tool steel

\begin{tabular}{cc}
\hline Tensile strength, U & $1200-1590 \mathrm{~N} / \mathrm{mm}^{2}$ \\
Tensile strength, Y & $1000-1380 \mathrm{~N} / \mathrm{mm}^{2}$ \\
Hardness HV & $290-370 \mathrm{HV}$ \\
Melting Point & $1427^{\circ} \mathrm{C}$ \\
Density & $7.8 \mathrm{~g} / \mathrm{cm}^{3}$ \\
\hline
\end{tabular}

The effects of microwave heating time on cladding development used for pilot study are presented in Table 2. It was observed that cladding at $810 \mathrm{sec}$ showed High standard metallurgical bonding with the substrate. Accordingly, the processing time of $810 \mathrm{sec}$ for the development of all the coatings.
For microstructural investigation of samples obtained from the two process, the samples were cut transversely from the section and polished as per standards. Then etching is done on polished samples with $10 \%$ of Nital Solution $\left(10 \mathrm{ml} \mathrm{HNO}_{3}\right.$ and $90 \mathrm{ml}$ Ethanol $\mathrm{C}_{2} \mathrm{H}_{6} \mathrm{O}$ ), and dried before SEM analysis.

Table 2 Effects of Microwave irradiation time on cladding development

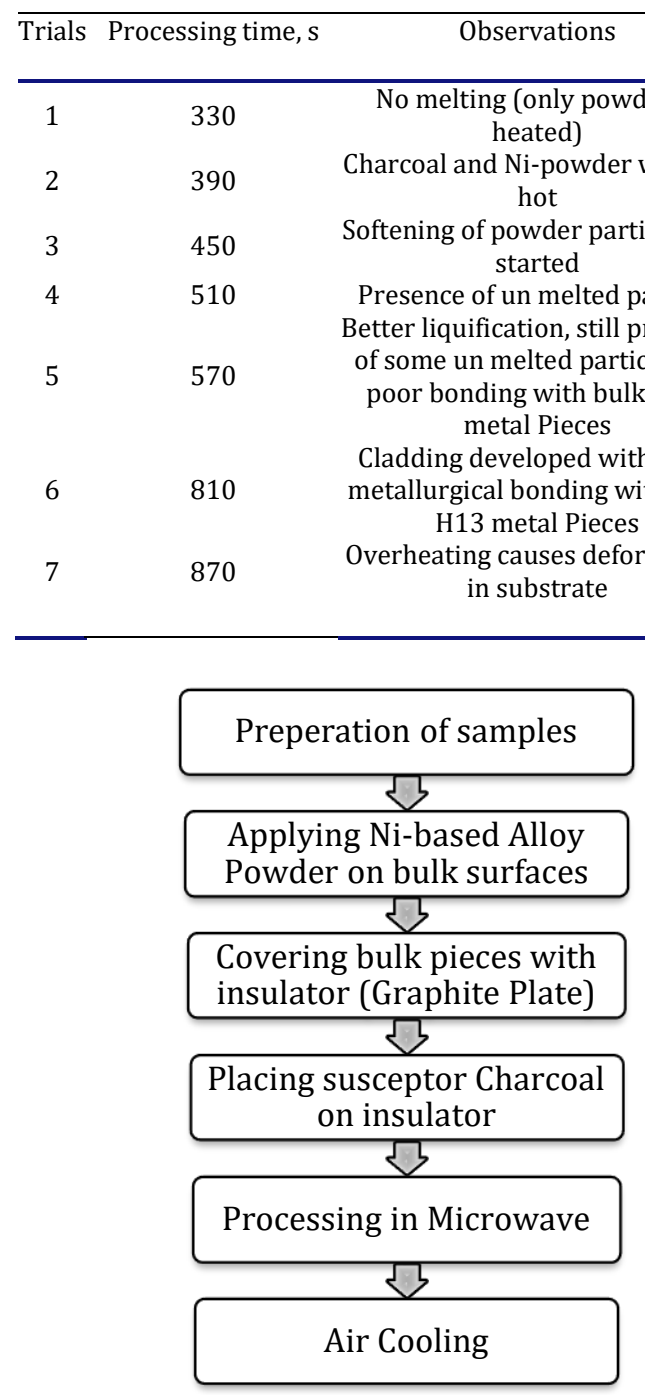

Fig 3 Typical flow chart of microwave Coating process

The wear mechanism of the worn-out surfaces of samples i.e. Unmodified, Nitrided, and Microwave coated H13 tool steel done after Pin on disc wear test, was also studied using SEM. The micro hardness of the unmodified, Nitrided, and Microwave Coated modified coatings was measured at a load of $100 \mathrm{~g}$ for $10 \mathrm{sec}$. The average microhardness of 6 readings at one sections of the Nitriding and coating per sample was used for study. The XRD using $\mathrm{Cu} \mathrm{K}_{\alpha}$ radiations of unmodified, nitrided and Microwave from $10^{\circ}$ to $100^{\circ}$ ( $2 \theta$ value) at a scanning speed of $1 \% \mathrm{~min}$ was used to identify various phases. 
Abrasive Wear Study of Unmodified, Modified (Gas Nitrided), Modified (Microwave Nickle Coated ) Was Performed using DUCOM (Pin on Disc) wear testing Machine, Wear Pins is of size $10 \times 10 \times 5 \mathrm{~mm}^{3}$ is held against the disk having Silicon carbide abrasive paper, The track radius is fixed at $60 \mathrm{~mm}$, and 400 revolution per minute (rpm) of rotating disc is calculated against the the sliding speed of $150.96 \mathrm{~m} / \mathrm{min}$. Abrasive wear test is divided into Three cases depending upon abrasive Paper Grit size and the specimen used, Table2 shows the Test Structure.

Table 2 Test Structure of Pin on Disc Wear Testing

\begin{tabular}{|c|c|c|c|}
\hline \multicolumn{4}{|c|}{ Test Structure } \\
\hline & Paper Grit Size & 220 & 1000 \\
\hline \multirow{2}{*}{1} & Unmodified H13 Tool Steel of size & 3 & 3 \\
\hline & $10 \times 10 \times 5 \mathrm{~mm}^{3}$ CASE A & nos. & nos. \\
\hline \multirow{2}{*}{2} & Modified (Nitrided) H13 Tool Steel of Size & 3 & 3 \\
\hline & $10 \times 10 \times 5 \mathrm{~mm}^{3}$ CASE B & nos. & nos. \\
\hline \multirow{2}{*}{3} & Modified (Nickle Coated) H13 Tool Steel of Size & 3 & 3 \\
\hline & $10 \times 10 \times 5 \mathrm{~mm}^{3} \mathrm{CASE} \mathrm{C}$ & nos. & nos. \\
\hline
\end{tabular}

The tester was allowed to run ideal for $1 \mathrm{~min}$ in order to obtain constant speed, and then a force of $10 \mathrm{~N} \sim$ $1 \mathrm{~kg}$ was put on the $\mathrm{H} 13$ pins.

The samples of all coatings were cleaned with acetone and then dried. The mass loss of all the coating was calculated by weighing all samples prior to and after the wear test on an electronic weighing balance of accuracy $0.0001 \mathrm{~g}$.

\section{Result and Discussion}

Each and every metal has got different mechanical and tribological properties. Some metals are sturdy, robust and strong, while others are much more ductile malleable and less tough. Steel are often require treatment to obtain maximum hardiness, capability and durability. We can change the mechanical properties of metals through selecting desired manufacturing process for getting desired property. One process of heat treatment is surface hardening. In this process, the metal surface is strengthened through the addition of a thin blanket of another element that increases durability and hardness of substrate. In many Industrial applications, such as guide pillar and guide bush in press tool, inner surface of injection molding, Metal gear, which requires hardness and ductility. case hardening has significant role to play

In this work, experiment has been carried out to compare the most general process of Case hardening i.e. Gas Nitriding and a new approach i.e. Microwave Coating on $\mathrm{H} 13$ tool steel through $\mathrm{MHH}$. H13 tool steel is the very versatile grade which is used in extrusion dies and other tooling components for production of standard aluminium profiles, Injection molding nozzle and barrel, which is characterized by good resistance to wear, high toughness, uniform and high machinability, high-temperature resistance, needs to be case hardened [Akhtar, et al, 2009].

The particle size of Ni-based powder used in this study ranges from 50 to 70 microns, but the skin depth at $2.45 \mathrm{GHz}$ of nickel powder is 0.12 microns, which is lower than the size of $\mathrm{Ni}$ powder to interact with microwave irradiation for the successful development of the coatings [Gupta et al 2011].

Thus, the coatings were developed using susceptor material i.e. charcoal powder and graphite sheet of thickness $1.5 \mathrm{~mm}$.

\section{3. a Wear Test}

It is clearly visible Fig- 4 that Case A Which Unmodified untampered H13 Tool Steel has got higher wear as compared with all other samples at both 220 and 1000 grit size paper, Case B which is modified Gas nitride Sample has higher rate of mass loss rather than Case $C$ but Lower than Case A at both 220 and 1000 grit size paper, Case C Which is Microwave Coated (Nickle) H13 Tool steel has lowest mas loss as compared to all other case at both Grit size Paper test.

To analyse the abrasive wear mechanism of all the samples i.e. Case A, Case B, Case C, The SEM Images of worn-out samples of Cases A-C were taken and are shown in figure. The results of the SEM images of the unmodified, modified (nitriding), modified (Coating) shows, ploughing, cutting, and crater formation on the worn-out surfaces. The mass loss of each sample depends on the hardness and wear mechanism taking place in various cases. During ploughing, ridges were formed along the wear track and the material was displaced sideways. In the cutting mechanism, small chips are formed as wear debris, whereas in the crater the material is removed due to which small cavities are formed, the SEM images of the Samples show that the worn grooves are wider due to coarse grit size.

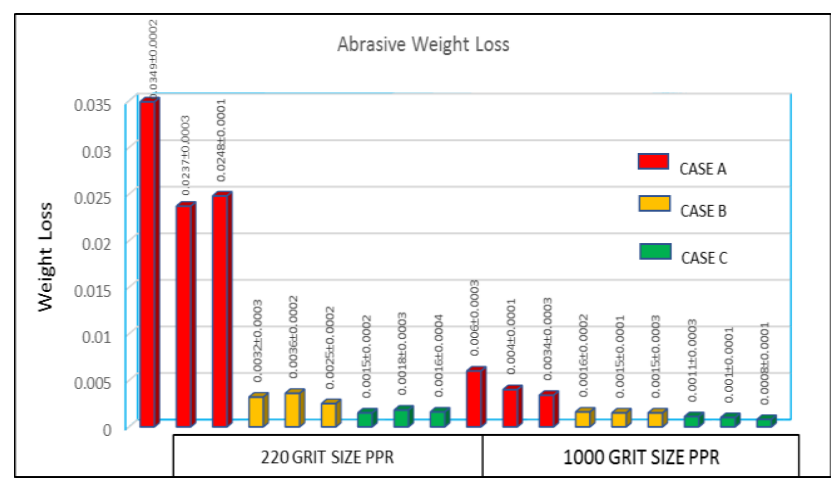

Fig 4 Abrasive Weight Loss 


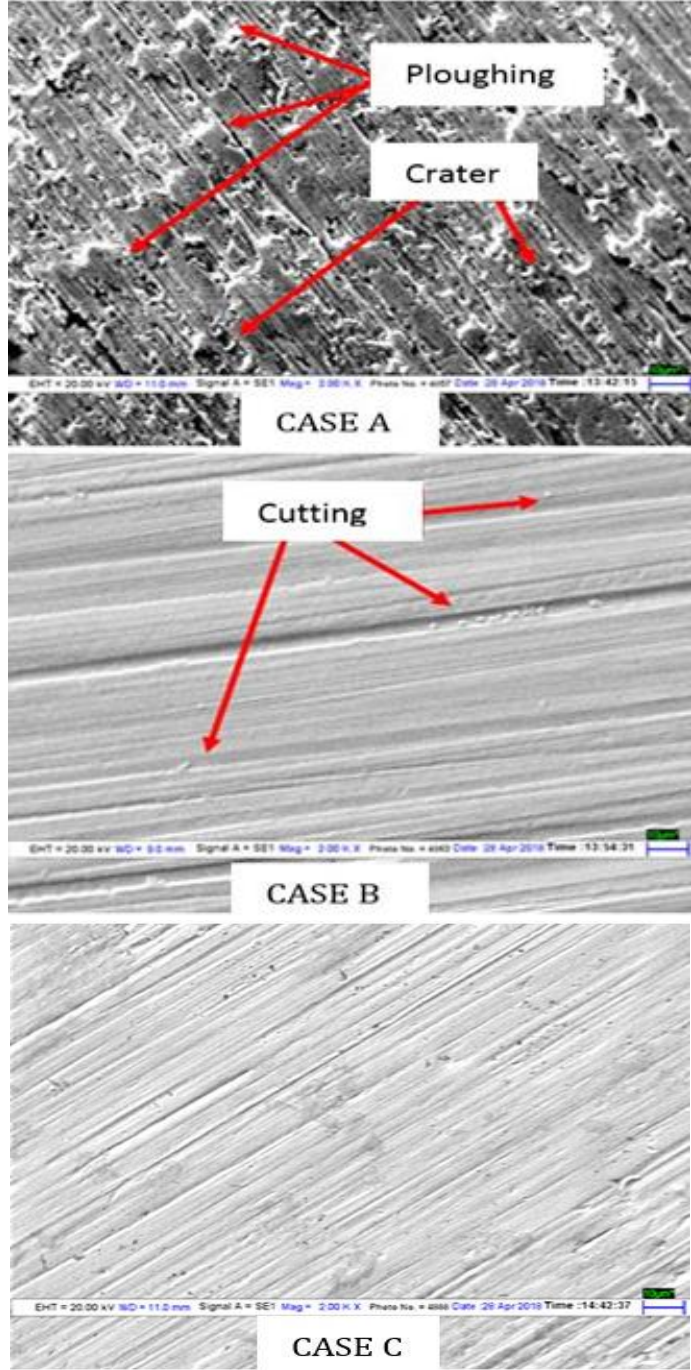

Fig 5 SEM Image to show worn out morphology of wear in the samples undergone through 220 Grit size paper Image taken at $10 \mu \mathrm{m}$
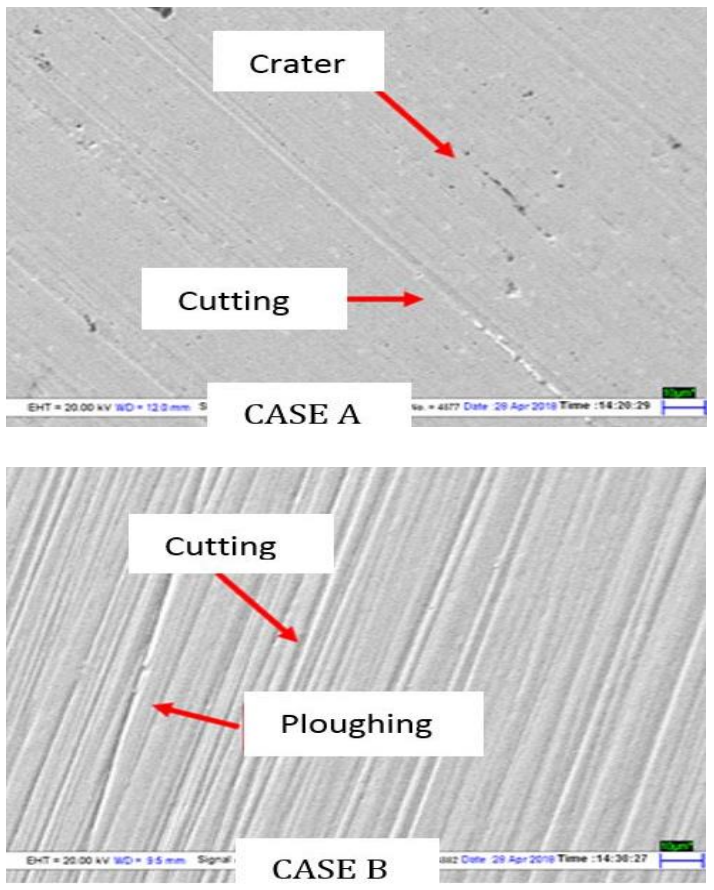

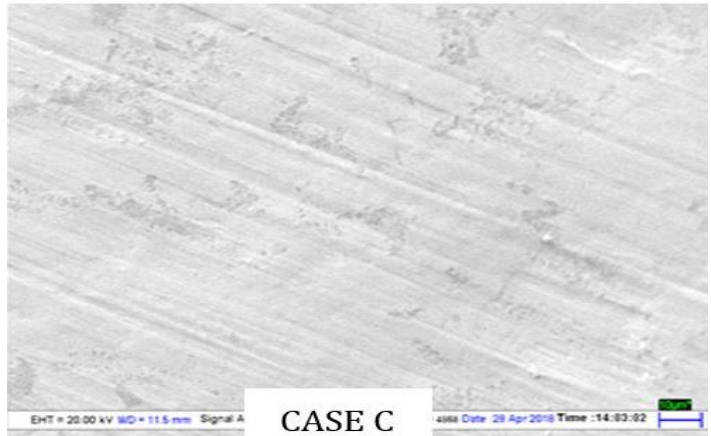

Fig 6 SEM Image to show worn out Morphology of wear in the samples undergone through 1000 Grit size paper, Image taken at $10 \mu \mathrm{m}$

\section{3. b Scanning Electron Microscope (SEM)}

The SEM cross-section picture of the sample (as shown in Fig- 7) reveals the presence of nitride precipitation and continuous compound layer. A White layer near the surface can be seen in SEM micrograph, which is the nitride layer. The diffusion zone exhibits a uniform distribution of nitrides depreciate slowly (somewhere abruptly) from surface to the core.

The depth of compound layer, which is considerably shallower, is an indication of controlled nitriding, as can be seen in the SEM micrograph (Figure-7). The depth of the compound layer ( as seen in SEM micrograph) is of the order of $12-18.4 \mu \mathrm{m}$, while the nitrided layer is about $165-180.5 \mu \mathrm{m}$ (Measured through Image Software). Image is taken at magnification of $150 \mathrm{X}$

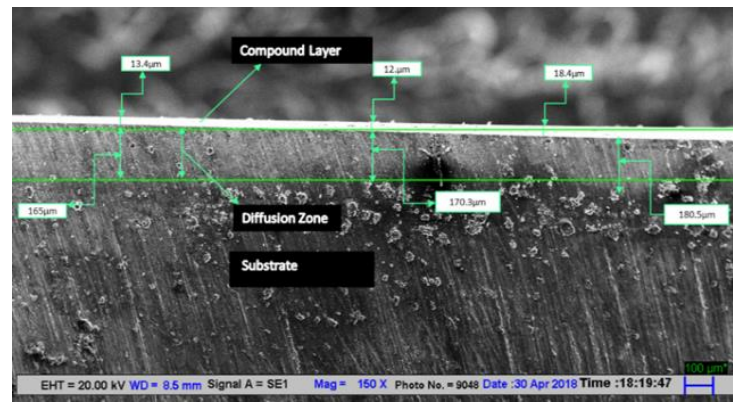

Fig 7 SEM Image of Transversely cut Nitrided Sample of H13 Tool Steel

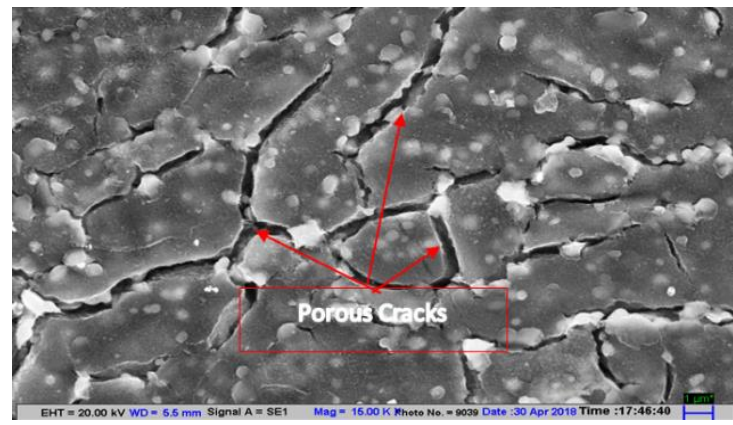

Fig 8 SEM Image of Nitrided Sample Showing its Morphology 
As from SEM Image from the top surface of the nitrided Sample of H13 Tool Steel It is clearly visible that A large number of pores and cracks is seen in the compound layer while nothing is visible in Nickle coated case (Fig-8 \& 9). This because the nitrogen atoms try to recombine to form $\mathrm{N}_{2}$ as the atoms has lower energy [yang, et al, 2011]. SEM Image is taken at $15 \mathrm{k}$ X.

The SEM analysis of Nickle Alloy Powder coated on H13 tool steel through MHH is shown on Fig- 9 and that of transversely cut coated $\mathrm{H} 13$ tool Steel (Ni-based alloy) is shown on (BSD mode) Fig-10, the scanning electron micrograph of Nickle based powder particles used for coating $\mathrm{H} 13$ tool steel has been shown. The Average Particle Size of Nickle based powder is $60 \pm 10$ $\mu \mathrm{m}$ which has been completely melted and formed metallurgical bond between the interfaces of $\mathrm{Ni}$ - clad and H13 tool steel piece, the coating is free from porosity and crack which is seen in nitrided samples so it has good mechanical property, wear strength and hardness as compared to nitrided samples, further, a dense and homogenous structure is formed, the molten powder melts interfacing surface of the substrate. The melting of the interfacing surface is limited to a thin layer only because of low skin depth of bulk material [Bansal, et al, 2013].

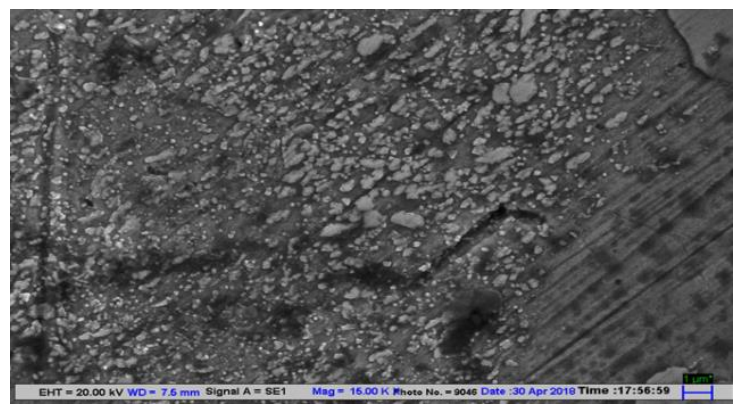

Fig 9 SEM Image of Coated (Nickle Sample) Showing its Morphology

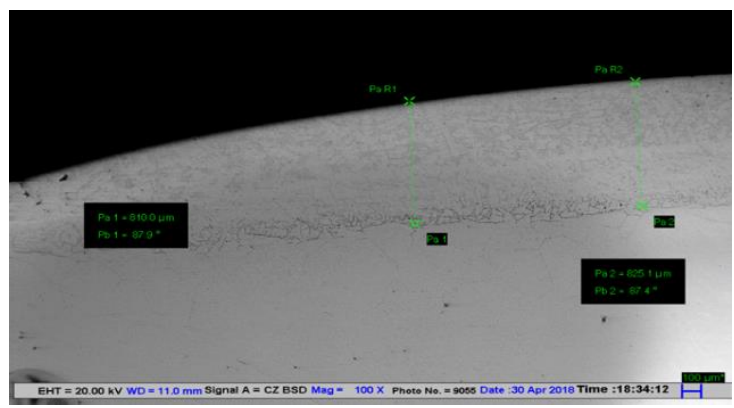

Fig 10 SEM image of transversely cut Coated (Nickle) H13 Tool Steel in BSD mode to show elements.

The average thickness of Clad is found in the range of $810-825.1 \mu \mathrm{m}$ i.e. $0.8 \mathrm{~mm}$ approx. from SEM investigation through Back Scattered Electron Detector mode. In BSD Mode it is clearly visible the thickness of clads as it distinguishes two elements easily. The susceptor material ingest microwave promptly at the room temperature until it reaches a higher temperature which is then transferred to coating powder via the conduction/radiation mode of heat transfer until it starts absorbing microwave radiation directly at higher temperatures normally between $400^{\circ} \mathrm{C}$ and $600^{\circ} \mathrm{C}$ which result in development of Cladding. The microstructure of Cladding consists of eutectic, Ni Grains and dendrite form.

\section{3. c X-Ray Diffraction (XRD)}

$\mathrm{X}$-Ray Diffraction is a crystallography technique which is used to find out the atomic and molecular form, shape, and composition of a crystal, when incident beam of X-rays bombards the surface of crystalline atom it diffracts into many specific direction. In this Experiment XRD Patterns are obtained through Bruker instrument $\mathrm{AXS}$ with $\mathrm{Cu}-\mathrm{K}_{\alpha}$ radiation. The Scan Rate is maintained at $1 \frac{\mathrm{o}}{\mathrm{min}}$ and the scan range from $10^{\circ}$ to $90^{\circ}$ of $2 \theta$.

The Typical XRD spectrum of H13 tool Steel used as a base metal for all comparison is shown in Fig 11, It is seen from the XRD spectrum that that few Iron Nitride $\left(\mathrm{Fe}_{2} \mathrm{~N}\right)$ is present in the surface of $\mathrm{H} 13$ tool steel which is strongest naturally magnetic material, and found in $\alpha-F e N$ state having BCC Structure of ferrite. The highest peak Corresponds to $2 \theta \sim 44.41^{\circ}$ shows the formation of Iron (II, III) oxide $\left(\mathrm{Fe}_{3} \mathrm{O}_{4}\right)$, known as mineral magnetite. Further peaks corresponding to $2 \theta \sim 82.16^{\circ}$ formation of Cementite $\left(\mathrm{Fe}_{7} \mathrm{C}\right)$, which improves the hardness of material. While other peaks have less intensity, peaks corresponding to $2 \theta \sim 82.01^{\circ}$ is Iron Disilicide $\left(\mathrm{FeSi}_{2}\right)$ and is found in $\beta-\mathrm{FeSi}_{2}$ Phase.

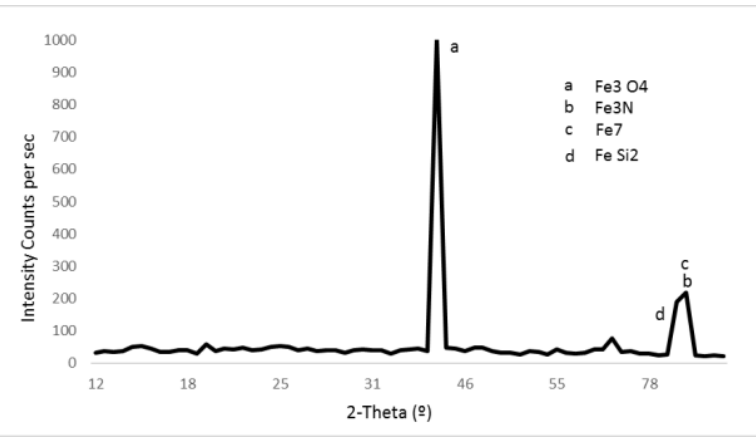

Fig 11 H13 Tool Steel XRD Spectrum

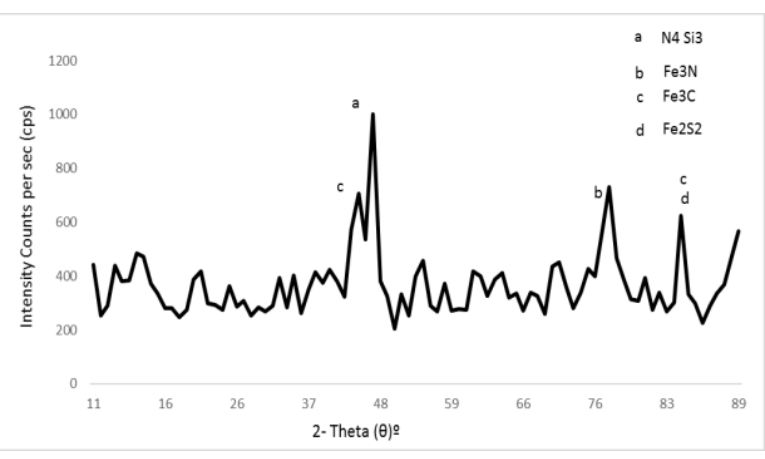

Fig 12 Nitrided H13 Tool Steel XRD Spectrum 
XRD spectrum of nitrided H13 tool Steel shown in Fig12, Gradual graph shows uniform and controlled Nitriding. It is seen from the XRD spectrum that presence of Iron Carbide in $\varepsilon$ - Phase, with small amount of chromium vanadium oxide. Highest peak corresponds to $2 \theta \sim 47.74^{\circ}$ which is consists of $\mathrm{N}_{4} \mathrm{Si}_{3}$ Silicon Nitrite in $\alpha$ \& $\beta$ Phase, which provides high melting point, High hardness and Thermal inertness to the crystal, Further Peak Correspond to $2 \theta \sim 76.99$ o Shows the formation of $\mathrm{Fe}_{3} \mathrm{~N}$ which is siderazot and is found in $\varepsilon^{-}$phase. Peak corresponds to $2 \theta \sim 44.58^{\circ}$ shows $\alpha$-Fe with cementite, and Chevral phase, this line also includes Iron carbide in cohenite which forms a hard, shiny, silver surface. Some traces of $\mathrm{Fe}_{2} \mathrm{~S}_{2}$ Iron sulphide is also found which is an impurity.

XRD spectrum of microwave coated H13 tool Steel shown in Figure- 13, It is seen from the XRD spectrum that there is a presence of lanthanum fluoride carbonate $\left(\mathrm{FLaO}_{3}\right)$ and Barium carbonate $\left(\mathrm{BaCO}_{3}\right)$ also called Witherite, the crystals are constantly twinned together in groups of three, which features pseudohexagonal forms somewhat looks like bipyramidal crystals of quartz. This forms helps in hardening of steel, as it act as a flux, a matting and crystallizing agent. Highest peak corresponds to $2 \theta \sim 50.96^{\circ}$ which is consists of Bismuth Ferrite $\left(\mathrm{BiFeO}_{3}\right)$ and Strontium Nickle Oxide $\left(\mathrm{NiO}_{2} \mathrm{Sr}\right), \mathrm{BiFeO}_{3}$ provides rhombohedral phases, another Peak Corresponds to $2 \theta \sim 43.94^{\circ}$ is Iron Nitride $\left(\mathrm{Fe}_{3} \mathrm{~N}\right)$ and also some traces of Cubic Boron Nitride $\left(\mathrm{C}_{2} \mathrm{BN}\right), \mathrm{Fe}_{3} \mathrm{~N}$ Provides HCP Structure to the crystal, which is in $\varepsilon$-Phase, $\mathrm{C}_{2} \mathrm{BN}$ is the hardest material after Diamond, Provide High Hardness to the Coating.

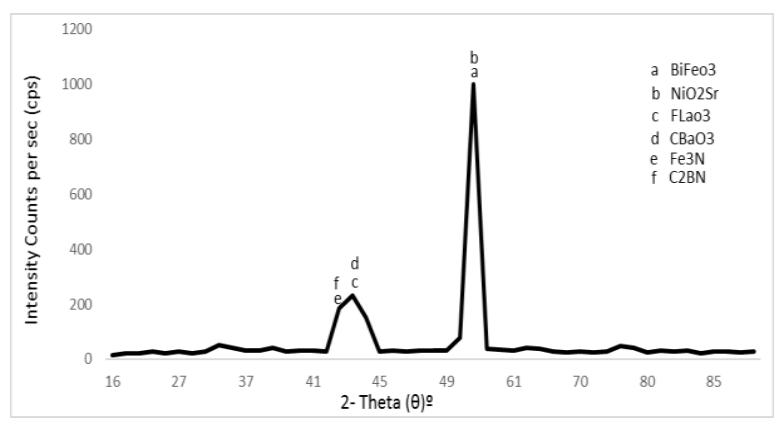

Fig 13 Coated (Nickle) H13 Tool Steel XRD Spectrum.

\section{3. d Microvicker's Hardness (Hv)}

Hardness of material has a great influence on the tribological and surface behaviour of all three specimen, for checking Hardness the Specimen is transversely cut and polished as per standard. Profile hardness on micro vicker's hardness is taken at 6 different points and average of the value is taken on HV Scale weight applied is $100 \mathrm{~g}$ for $10 \mathrm{sec}$. Mitutoyu MVK$\mathrm{H} 1$ Instrument is used to measure micro vicker's hardness.
Table 3 Hardness $\mathrm{HV}_{0.1}$

\begin{tabular}{ccc}
\hline & Specimen & Hardness \\
\hline 1 & Unmodified Untreated H13 TS & 185.5 \\
2 & Unmodified and Heat treated (nitriding) & 610 \\
3 & Unmodified and Heat treated (Coating) & 573 \\
4 & Modified Nitrided H13 TS at Nitrided zone & 829.5 \\
5 & Modified Coated Nickle H13 TS at Coating & 788 \\
\cline { 2 - 3 }
\end{tabular}

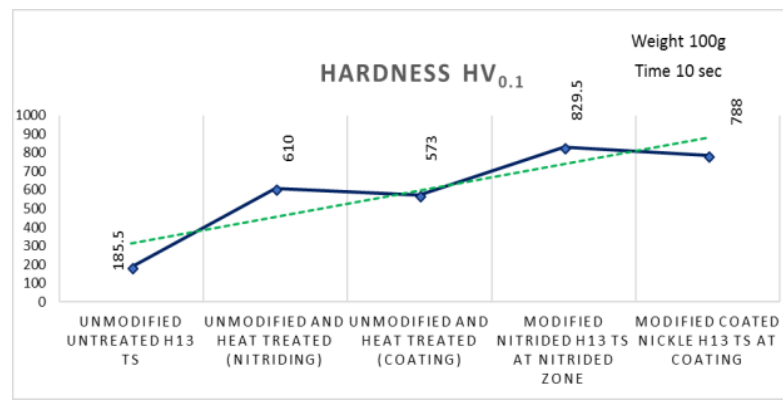

Fig 14 Hardness Profile graph $\left(\mathrm{HV}_{0.1}\right)$

\section{Conclusion}

It is very difficult task to coat metallic material using microwave energy as metallic material does not absorb microwaves at room temperature. In this present experiment nitriding of $\mathrm{H} 13$ Tool Steel metallic piece through Gas nitriding and microwave coating of Nickel on H13 Tool Steel through microwave hybrid heating in a $900 \mathrm{~W}$ microwave system of Frequency $2.45 \mathrm{Ghz}$.

The Major Conclusion drawn from present Work are Discussed Below.

1) Case Hardening of H13 Tool Steel Through Gas Nitriding is Successfully done in Total 120 Hrs.

2) Case Hardening of H13 Tool Steel Through Microwave Coating Is Successfully done in $810 \mathrm{Sec}$.

3) SEM Image Of Nitrided Sample has Some pores and crack but Nickle coated H13 Tool steel doesn't show these defects.

4) Interfacing at Coating Zone shows Good Metallurgical bonding with the substrate material i.e. H13 Tool Steel.

5) The Interfacing Layer of Nickle Powder is completely melted but melting of interfacing surfaces of H13 Tool Steel is limited to only thin layer due to low depth penetration of surface by microwaves in bulk material.

6) Coating Has the Hardness of HV0.1 788 and Gas Nitriding is of HV0.1 829.5.

7) Due to excellent melting in Coating of Nickle Through MHH it has got perfect interface bonding.

8) Hardness of gas nitrided sample is Little more than of Coating but coating has little high Wear resistance than Gas nitriding.

9) Hardness of microwave coated sample can be increased by increasing the microwave time. 


\section{Acknowledgement}

The author acknowledges M/s Coatwell India Pvt. Ltd, India, to provide Gas Nitriding Facility for research work. The authors are also thankful to Mr. Kuldeep, SEM Lab, Dept of Textile Engineering Indian Institute of Technology, New Delhi for SEM, XRD and EDX studies.

\section{References}

A.E. Zeghni . and M.S.J. Hashmi (2005), The Effect of Coating and Nitriding on the Wear Behaviour of Tool Steels. Journal of Materials Processing Technology, 155-156, 1918-1922

K. Singh \& S. Sharma (2016), Development of Ni-based and CeO2modified coatings by microwave heating, Materials and Manufacturing Processes, ISSN: 1042-6914, 1532-2475 (Online) Journal.

S. S. Akhtar \& A. F. M. Arif \& B. S. Yilbas (2009), Evaluation of gas nitriding process with in-process variation of nitriding potential for AISI $\mathrm{H} 13$ tool steel, International Journal of Advance Manufacturing and Technology, 47,687-698

S.H. Yeh, L.H. Chiu, H. Chang (2011), Effects of Gas Nitriding on the Mechanical and Corrosion Properties of SACM 645 Steel, Engineering, 3, 942-948

S. Chandrasekaran, S. Ramanathan, and T. Basak (2012), Microwave Material Processing-A Review, Journal Review AIChE J, 58: 330-363,

B. Yahaya, S. Izman, M. Konneh, N Redzuan (2014), Microwave Hybrid Heating of Materials Using Susceptors- A brief review, Advanced Materials Research Vol. 845 pp 426-430

H. Ollendorf, D. Schneider (1998), A comparative study of adhesion test methods for hard coatings, Surface and Coatings Technology 113 (1999) 86-102

S. S. Akhtar \& A. F. M. Arif \& B Sami Yilbas (2009), Evaluation of gas nitriding process with in-process variation of nitriding potential for AISI H13 tool steel, International Journal of Advance Manufacturing and Technology, 47,687-698

J. Yang, Y. Liu, Z. Ye, D. Yang, Shiyu He (2011), Microstructural and tribological characterization of plasma- and gas-nitrided 2Cr13 steel in vacuum, Materials and Design, 32 ,808-814

S. Singh, D. Gupta, V. Jain (2015), Recent applications of microwaves in surface coating and material joining; Journal of Engineering manufacture, Review Article, 1-15

D. Agarwal (2010), Latest global development in the field of microwave processing; Material research innovations, Vol 14 No 1

S. P. Kochhar A.P. Singh (2011), Developments in Microwave Processing of Materials, Asian Journal of Chemistry, Vol. 23, No. 8, 3307-3312

M. Yang (2012), Nitriding - fundamentals, modelling and process optimization, Worcester Polytechnic Institute.

D.U. Hong, M. A. J. Somers , J. Agren (2000), Microstructural and compositional evolution of compound layers during gaseous nitrocarburizing, Metallurgical and Materials Transactions A,31:195

D. Pye (2003), Practical nitriding and ferritic nitrocarburizing, Materials Park, OH: ASM International. ISBN: 0-87170-791-8

B. Wang (2016), An Investigation Of The Adhesion Behavior Of Aluminum On Various PVD Coatings Applied To H13 Tool Steel To Minimize Or Eliminate Lubrication During High Pressure Die Casting. Journal of Materials Processing Technology.

F. Czerwinski (2012), Thermochemical Treatment of Metals, Thermochemical Treatment of Metals, Intech

M. Avijit, U. Anish (2009), Microwave heating of pure copper powder with varying particle size and porosity, Journal of Microwave Power Electromagnetic Energy, ISSN: 0832-7823 (Print) (Online) Journal
M. Oghbaei, O. Mirzaee (2010), Microwave versus conventional sintering: a review of fundamentals, advantages and applications; Journal of Alloys and Compound, 494, 175-189

A. M. Hebbale M.S. Srinath (2016), Microstructure and Experimental Design Analysis of Nickel Based Clad Developed Through Microwave Energy, Perspectives in Science S22130209(16)30066-0;

R.B. Lohit. M. Bhovi (2017), Development of Ni-WC composite clad using microwave energy, Materials Today: Proceedings, 4 2975-2980.

J. Hardell, B. Prakash (2008), High-temperature friction and wear behaviour of different tool steels during sliding against $\mathrm{Al}-\mathrm{Si}$ coated high-strength steel, Tribology International 41, 663671

M. A. Terres, L. Ammari, A. Chérif (2017), Study of the Effect of Gas Nitriding Time on Microstructure and Wear Resistance of 42CrMo4 Steel, Materials Sciences and Applications, 8, 493-507

A. Zhecheva, W. Sha, S. Malinov, Ad. Longa (2005), Enhancing the microstructure and properties of titanium alloys through nitriding and other surface engineering methods, Surface \& Coatings Technology, 2192- 2207

S. Kaushal, D. Gupta, H. Bhowmick (2016), On microstructure and wear behavior of microwave processed composite clad, Journal of Tribology.

S. Kaushal, V. Sirohi, D. Gupta, H. Bhowmick and S. Singh (2015), Processing and characterization of composite cladding through microwave heating on martensitic steel, Journal of Materials: Design and Application; 0(0) 1-7

V. Sirohi (2015), Surface Modification Of Martenistic Stainless Steel Through Microwave Hybrid Heating; Journal of Materials: Design and Applications.

D. Agarwal (2006), Microwave sintering, brazing and melting of materials, Advanced Processing of Metalsa and Materials, Volume 4

A. Prasad, D. Gupta, M. Ravi Sankar, A. N. Reddy (2014), Experimental Investigations of $\mathrm{Ni} / \mathrm{La}_{2} \mathrm{O}_{3}$ Composite MicroCladding on AISI 1040 Steel through Microwave Irradiation. All India Manufacturing Technology, Design and Research Conference, 55, 1-6

D. E. Clark, D. C. Folz, J. K. West (2000), Processing materials with microwave energy; Materials Science and Engineering A287, 153-158.

S. Aravindan, R. Krishnamurthy (1999), Joining of ceramic composites by microwave heating; Materials Letters 38, 245249

G.S. Fox-Rabinvich, L. Shuster, G.K. Dosbaeva,(2001), Impact of ion modification of HSS surfaces on the wear resistance of cutting tools with surface engineered coatings, Wear 294, 1051-1058.

D. Gupta, A.K. Sharma (2011), Development and microstructural characterization of microwave cladding on austenitic stainless steel, Surface and Coatings Technology, 205 (21-22), 51475155.

SP Dwivedi, S Sharma (2014), Effect of Process Parameters on Tensile Strength of 1018 Mild Steel Joints Fabricated by Microwave Welding, Metallogr. Microstruct. Anal, Springer Science and ASM International, 3:58-69

M.S. Srinath, A. K. Sharma and Pradeep Kumar (2011), A new approach to joining of bulk copper using microwave energy, Materials and Design $32,2685-2694$

A. Bansal, A. K. Sharma, S. Das (2013), Metallurgical and mechanical characterization of mild steel-mild steel joint formed by microwave hybrid heating process, Indian Academy of Sciences, pp. 679-686.

D. Gupta, A.K. Sharma (2011), Copper coating on austenitic stainless steel using microwave hybrid heating, J. Process Mechanical Engineering, Proc. IMechE Vol. 226 Part E 